\title{
Wireless Communication Using Embedded Microprocessor-5G Embedded E-Commerce System Oriented to Fruit Ordering, Sales, and Logistics
}

\author{
Tung-Chun Chen $\mathbb{D}^{1,2}$ Yu-Shen Liang, ${ }^{1}$ Po-Sheng Ko $\mathbb{D}^{3},{ }^{3}$ Ping-Tsan Ho $\mathbb{D},{ }^{4}$ \\ and Jui-Chan Huang $\mathbb{D}^{5}$ \\ ${ }^{1}$ Department of Plant Industry, National Pingtung University of Science and Technology, Pingtung 91201, Taiwan \\ ${ }^{2}$ Department of International Business, National Kaohsiung University of Science and Technology, Kaohsiung 82444, Taiwan \\ ${ }^{3}$ Department of Public Finance and Taxation, National Kaohsiung University of Science and Technology, \\ Kaohsiung 82444, Taiwan \\ ${ }^{4}$ Department of Tourism Management, National Kaohsiung University of Science and Technology, Kaohsiung 82444, Taiwan \\ ${ }^{5}$ Yango University, Fuzhou 350015, Fujian, China \\ Correspondence should be addressed to Ping-Tsan Ho; k0630@staff.nkuht.edu.tw
}

Received 4 December 2021; Revised 7 January 2022; Accepted 20 January 2022; Published 18 February 2022

Academic Editor: Haibin Lv

Copyright (c) 2022 Tung-Chun Chen et al. This is an open access article distributed under the Creative Commons Attribution License, which permits unrestricted use, distribution, and reproduction in any medium, provided the original work is properly cited.

\begin{abstract}
With the birth of the Internet, information and data can flow in both directions, and, after that, it has spread to thousands of households. On this basis, e-commerce was also born, and it took a very short time from the field that no one cared about at the beginning to the hot focus field now. The development of e-commerce has broadened the sales channels of farmers, which has further increased the sales benefits of fruits and other agricultural products, conformed to the development of the times, and further supplemented the sales of fruits and other agricultural products. Based on the use of embedded microprocessors, this paper constructs an e-commerce system integrating sales and logistics. Based on the logistics model in the e-commerce platform, an e-commerce logistics identification model is constructed to measure the e-commerce logistics service level of agricultural products such as fruits. The article analyzes the sales and transportation methods of fruits and other agricultural products. Through a detailed analysis of the traditional e-commerce system, the e-commerce sales system has been optimized and improved by combining the reference cases and the data obtained from the Internet, especially in the aspect of logistics transportation. According to the data experiments in this article, it is shown that, after using the data formula for calculation, the best plan for transporting fruits and other agricultural products can be obtained. In the calculation result of the formula, the cost of delivery without considering customer satisfaction is 586 yuan, and the average delivery time of the vehicle is 5.625 hours, but the average satisfaction is only $78.5 \%$. Compared with customer satisfaction, although the cost is about 15 yuan more and the delivery time is a few minutes longer, the customer satisfaction is about $21 \%$ higher than the customer satisfaction without considering the customer. Based on the optimized and transformed e-commerce system, this article will further improve the e-commerce platform for fruits and other agricultural products.
\end{abstract}

\section{Introduction}

In recent years, with the continuous improvement of online transaction credit mechanism, online payment system and logistics and distribution system, and the change of consumer group characteristics, the e-commerce industry has achieved a strong development and started to enter a stable development stage. As the proportion of Internet technology in people's daily life has gradually increased, many new fields have been born [1]. Based on this working environment, the birth of e-commerce has been accelerated, and this model has gradually been integrated into people's work. As an 
important representative of the information age, computers are rapidly infiltrating various industries. Online shopping has become a way of life for modern young people and has caused tremendous changes in the production and business models of various industries. This article takes fruits as the sales object and uses wireless communication technology with embedded microprocessors to design an integrated electronic sales process for fruits from storage to logistics, starting research from two aspects: technical design and sales based on market environment.

With the progress of e-commerce in recent years, the sale of goods has become the hottest topic in the e-commerce industry. For example, He C. pointed out that, in recent years, with the rapid development of e-commerce, the service form of warehousing has undergone qualitative changes, and the integration of warehousing and distribution has become a necessary condition for the development of e-commerce logistics. The establishment of a sales forecast model is the most important link in the e-commerce supply chain. From the perspective of the supply chain, the integration of logistics can reduce costs and improve the logistics structure, which is a necessary trend for future development and growth [2]. Considering that the degree of e-commerce in the food, beverage, and alcohol industries is not as good as other categories, Ito M. proposed that there is still room for expansion in the online trading market for such products. The import volume of fruits and vegetables is increasing, which means that the direct-to-store or direct-to-consumer logistics methods should continue to expand. While agricultural producers are positioned to grow fruits and vegetables that are different from imported agricultural products, they have the opportunity to use online channels for sales, mainly processed products. Given the tight business environment, it cannot be said that a large number of family farms are expected to grow in the future; however, it is speculated that agricultural organizations and online markets for fruits and vegetables and related processed products will grow. According to the market development in recent years, the number of organizations that develop agriculture is still increasing. With the continuous development of online channels, the people's demand for fruits and vegetables continues to increase, and it is expected that the market for melons and fruits will continue to expand in the future [3]. In recent years, fresh vegetables and fruit products have been widely circulated in major cities in China through e-commerce in the form of a combination of fresh agricultural products. Shaosheng analyzed the preferences of Chinese consumers for specific FPP attributes. A method of choice experiment is used to explore consumer preferences. The authors found that, among the four attributes considered, the diversity of certification and FPP has a significant impact on consumers' willingness to pay (WTP). Residents have different preferences for FPP diversity and certification, but when considering fresh produce in FPP, certification is the main issue. For the WTP of the combination of attributes, the WTP values of the "green" and "organic" attributes are higher, while the WTP of the diversity of FPPs is lower. This research attempts to explore preferences for the first time and provides a corresponding algorithm, but the accuracy of the algorithm is not high [4]. After analyzing the supply chain and transportation cost of the goods, need to change thinking, and study based on the wireless communication of $5 \mathrm{G}$ embedded microprocessor, Nir K. said that $5 \mathrm{G}$ service itself or in combination with other technologies may have a transformative impact on e-commerce activities. After using 5G, the service efficiency of e-commerce and the sales of goods have been greatly improved [5]. According to Hasanat M. W., e-commerce is the sale and purchase of goods and services through an electronic network called the Internet. In this era, the survival of every enterprise is highly dependent on sales. If a company wants to get the highest sales, it is very important to have a strong SEO (search engine optimization) strategy. The research aims to optimize e-commerce through the implementation of social media and SEO technologies to increase retail sales. Optimizing e-commerce by implementing SEO techniques and social media in the retail business can help boost sales. The results show that the implementation of social media and search engine optimization technology helps to promote the development of retail business, but the degree of improvement is limited, and the income is not proportional to the effort [6]. Some experts have also begun to study e-commerce platforms. For example, Ma X. proposed that e-commerce platforms have typical bilateral market characteristics. The e-commerce platform provides real-time communication services for buyers and sellers. The development and implementation of bilateral strategies will affect the trading choices of traders and customers on the platform. This result will directly affect the trading value of the platform. Then, the article constructed an econometric model and empirically analyzed the impact of e-commerce platforms. An e-commerce platform is a platform that connects suppliers, manufacturers, distributors, and users based on various rules. Blockchain technology can be used as an auxiliary technology to adapt to supply chain management, and it is the main factor driving the market power of enterprises [7]. According to the management of different industries, different methods and countermeasures are suggested. In the e-commerce platform, attention should be paid to the quantity, price, and quality of products. Leung K. H. pointed out that, in today's digital world, the globalization of e-commerce business has not only changed our shopping habits but also brought tremendous changes to the entire retail and logistics industry. Due to the irregular acquisition mode of e-commerce orders, the limited time for service centers to process orders, and the guaranteed delivery schedule provided by e-retailers, for example, delivery on the same day or the next day after placing the order, logistics service providers (LSPs) must process outsourcing e-commerce logistics orders very effectively. If the execution process is not repeated, it will be difficult for the LSP to execute executable commands due to strict operational requirements, which will delay the next process in the supply chain. In view of the need to improve the handling of e-commerce orders, this research is reevaluating the implementation of e-commerce orders in distribution companies. Genetic algorithms (GA) are used to support e-commerce licensing and law enforcement technologies 
and integrate warehousing concepts into the new cloudbased electronic compliance application system (CEPS) [8]. However, although this method can increase the operating speed, it has higher requirements for operating equipment and higher requirements for the configuration of processing equipment.

In recent years, with the continuous improvement of online transaction credit mechanisms, the continuous improvement of online payment systems and logistics distribution systems, and the changes in the characteristics of consumer groups, China's e-commerce industry has achieved relatively strong development and has begun to enter a stable development stage. More and more companies are catching on the fast train of e-commerce development and entering this emerging industry. However, both European and American countries, which developed e-commerce earlier, or China, which has achieved good results in the e-commerce industry, has encountered difficulties in logistics and transportation. Through the use of embedded microprocessors and integrated fruit-based commercial systems, the analysis and calculation of e-commerce data can be made faster. In the modern e-commerce system, based on the use of embedded microprocessors, it is possible to analyze in more detail the influence of the supply chain, transportation route, order receipt, sales, transportation, and so forth of the fruit on the value of the product itself based on the use of embedded microprocessors, which can reduce costs and increase revenue [9].

The innovations of this paper are reflected in the following: (1) Introduction of embedded microprocessors. Compared with ordinary computers, computer systems equipped with embedded microprocessors have the advantages of low cost, high efficiency, and fast calculation speed. (2) Analyzing the construction of e-commerce system. (3) Introduction of the business model of fruits and other agricultural products. (4) Carrying out the experimental analysis of the distribution algorithm of fruits and other agricultural products.

\section{E-Commerce System and the Use of Embedded Microprocessors}

2.1. Embedded Microprocessor. The embedded microprocessor evolved from the central processing unit in the computer. Embedded microprocessors basically have 32 and above processing bits, so they have higher performance. Because the processor has strong processing performance, the corresponding reforms are also higher. However, the difference from the computer is that the embedded microprocessor deletes the functions irrelevant to the embedded system in the actual application. Because the unnecessary work of other parts is removed, the requirements of low power consumption and high efficiency embedded are realized. Compared with normal computers, computer systems equipped with embedded microprocessors have the advantages of low cost, high efficiency, and fast computing speed [10].

The basic layer of an embedded system is a built-in microprocessor. The biggest difference between embedded microprocessors and normal CPUs is that systems equipped with embedded microprocessors are customized systems for specific users. The card board integrated in the chip promotes the simplification of system design, while also having high efficiency and reliability [11]. Among them, the embedded system has the characteristics of strong specialization, small size, good real-time performance, good tailorability, high reliability, and low power consumption.

Embedded microprocessors have many systems. Even in the same system, different interfaces and external devices can be connected according to the clock frequency and bus size [12]. According to incomplete statistics, there are approximately thousands of microprocessors and dozens of system architectures in the world. But there is no embedded microprocessor that can be called the market leader, because the functions of the embedded microprocessor are designed according to the needs of customers, and one processor cannot satisfy all users $[13,14]$. As shown in Figure 1, it is the structure diagram of the embedded microprocessor.

2.2. E-Commerce Data. E-commerce is a new business model based on browser/server applications that recognizes customers' online purchases, online transactions between merchants, online payments, and network services. The payment method can be determined through electronic money, software wallet, smart card, or credit card, and, according to the customer's request information, the purchased goods can be quickly sent to the destination in the right way and at the right time. Normally, when an e-commerce company is established, its business scale is not large and its growth direction is not clear. With the popularity of online shopping and the continuous expansion of the online shopping market, the business scale of enterprises will explode [14].

As shown in Figure 2, as early as 2004, domestic and foreign e-commerce platforms have already had a corresponding scale, with sales of 61.1 billion US dollars. Compared with the domestic JD e-commerce platform, the sales volume in 2012 was only 60 billion yuan, indicating that the sales gap between domestic and foreign sales was not small at that time [15].

As shown in Figure 3, in the early 2010s, e-commerce attracted the attention of more and more people. After this, the number of transactions has been increasing rapidly on Double 11 every year. Although, compared to foreign countries, China's e-commerce started relatively late, the market is developing very rapidly [16].

2.3. Construction of the E-Commerce System. Traditional e-commerce often includes purchasing management, product warehousing functions, product sales management, and financial management functions. The e-commerce constructed in this paper is based on the traditional business model to be transformed, adding functions such as order acceptance, sales, and logistics services [17]. Embedded microprocessors play a major role in the construction of e-commerce systems. The embedded microprocessor can complete multiple tasks 


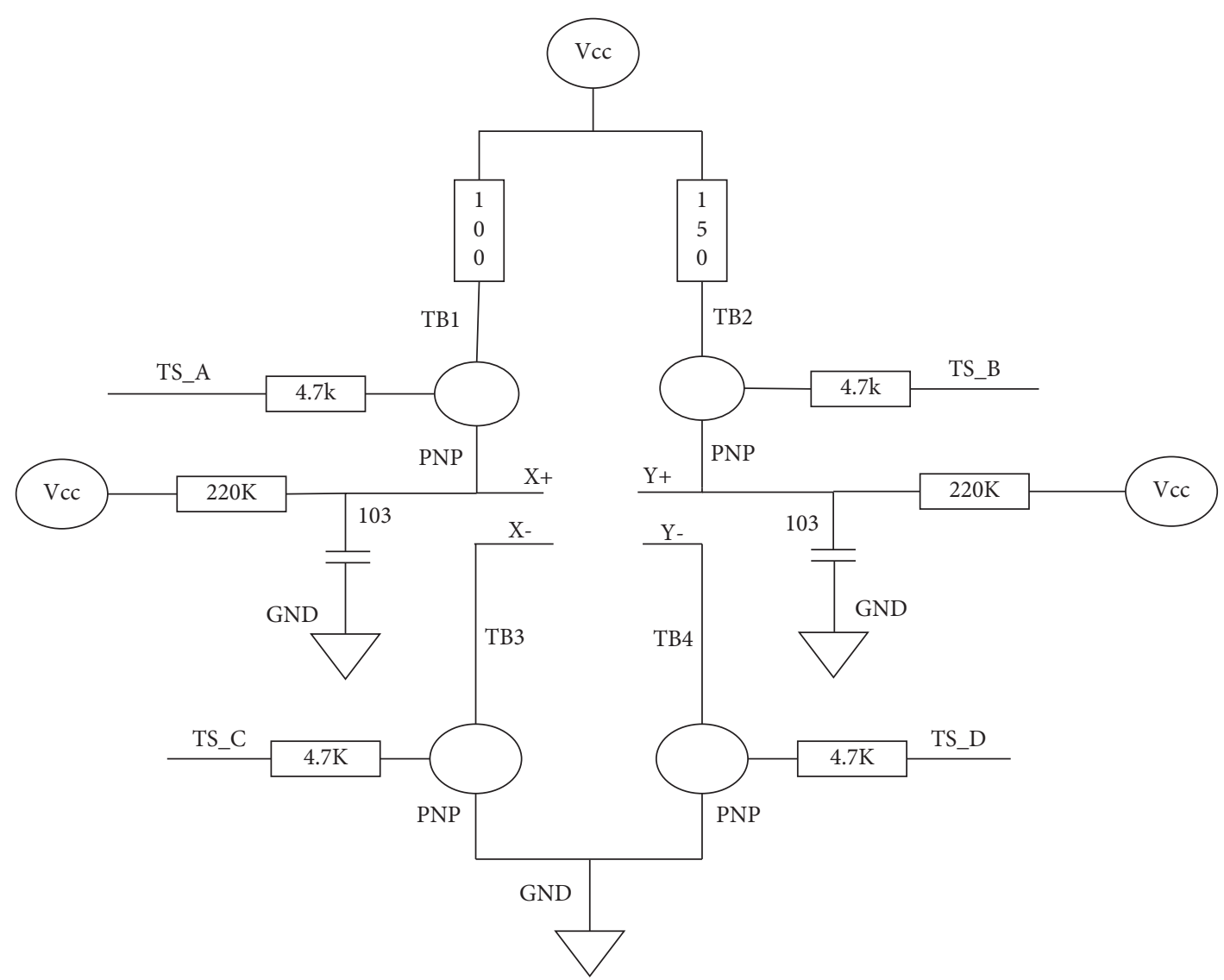

FiguRE 1: Embedded microprocessor.
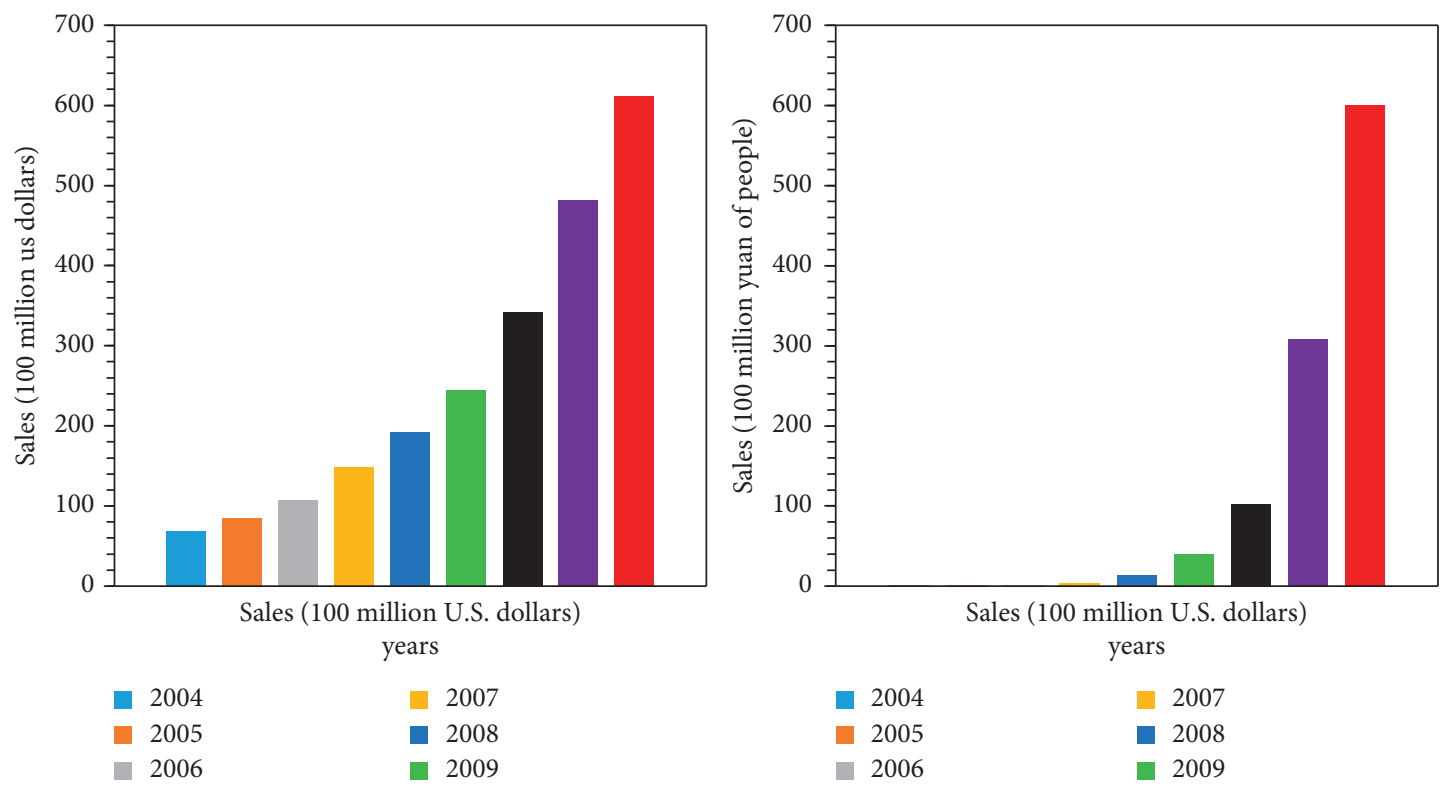

Figure 2: Diagram of e-commerce sales at the beginning of the century.

and has a short interrupt response time, thereby reducing the execution time of the internal code and real-time core to a minimum, thereby improving its efficiency. The accrual process is shown in Figure 4.
2.3.1. Logistics System. Compared with other system platforms, the e-commerce system platform using the embedded microprocessor has higher working stability, lower power consumption, strong adaptability to the environment, and 

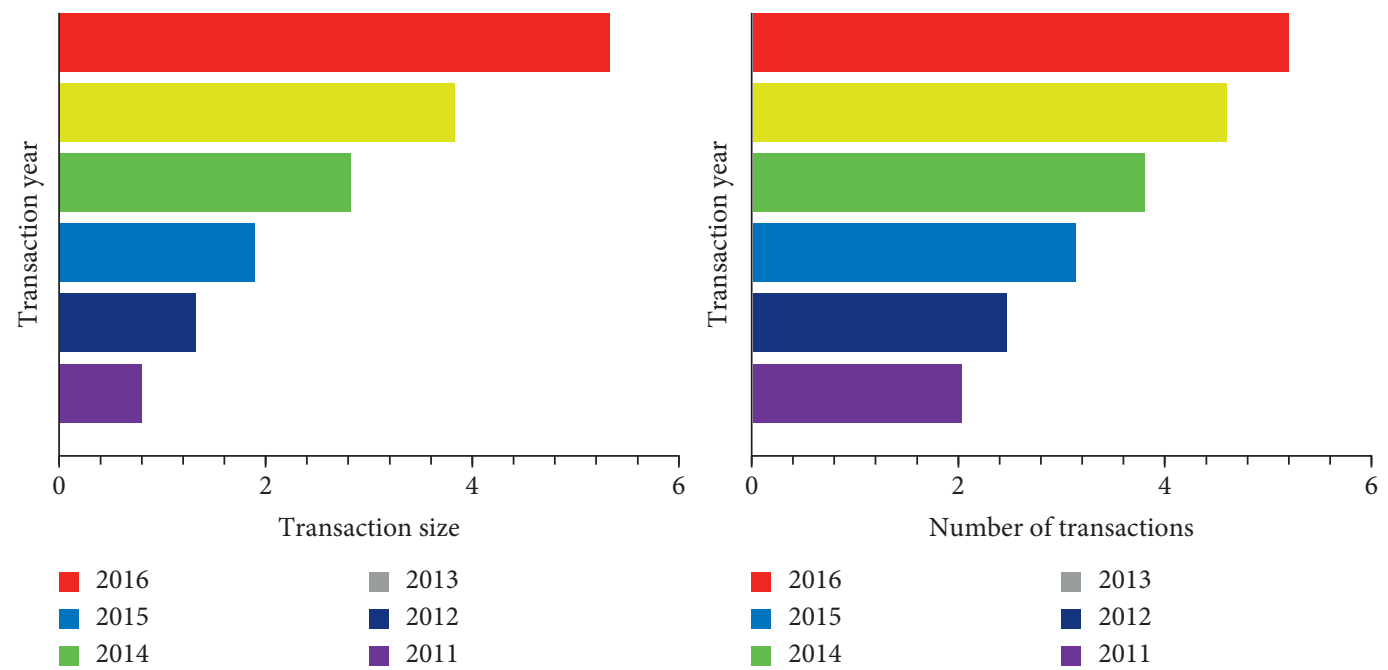

Figure 3: The scale of the online retail market and the number of transactions from 2011 to 2016.

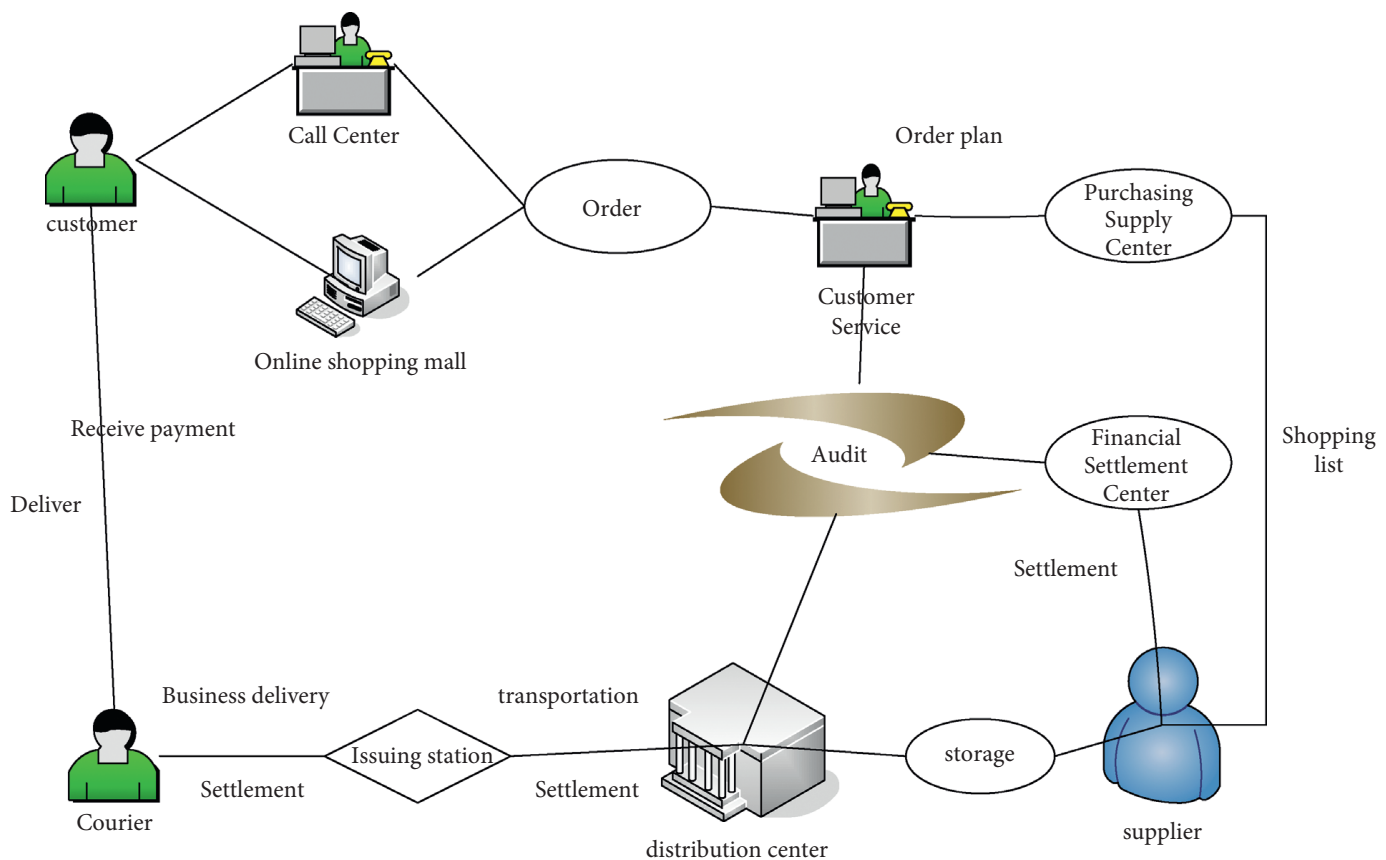

FIgURE 4: Diagram of the e-commerce operation mode.

smaller size. Based on the logistics model in the e-commerce platform, an e-commerce logistics identification model is constructed to measure the e-commerce logistics service level of agricultural products such as fruits [8]. According to research, it is necessary to establish a professional marketing service platform for fruit and other agricultural products, improve the supply chain network of fruit products, improve the information level of electronic logistics and transportation of fruit and other agricultural products, and increase the management level of fruit products and logistics information management. According to the investigation of the factors affecting transportation and sales of e-commerce, it is found that e-commerce platforms can solve the problem of supply and demand of fruit products. The construction of e-commerce is affected by three infrastructures. These three factors are basic equipment, external environment, and internal forces [18]. The e-commerce system based on embedded microprocessor plays a good role in logistics and transportation and has better safety performance.

2.3.2. Information System. Taking China's promotion of the establishment of a government-led agricultural information system as the basic idea and then, according to the development experience of other countries combined with the country's national conditions, an information system for agricultural products such as fruits is established, the product information market is standardized, information is 
collected, and comprehensive information services are provide, and then the construction of infrastructure is sped up, the service quality of fruits and other agricultural products is improved, the problem of balance of fruits and agricultural products is solved as soon as possible, and management and distribution construction is strengthened. An understanding of agricultural information is established, strong information talents are cultivated, and the development of China's fruit product business is promoted [11].

2.3.3. Legal System. The establishment of a legal e-commerce legal system for fruit products will facilitate the implementation of fruit return services, increase the income of fruit farmers, increase the transaction volume of fruit and other agricultural products, and promote China's economic growth. On the basis of the protection of farmers' economic rights and interests, the legal awareness of fruit farmers is trained, and the legal system of the Cybersecurity Law has strengthened the concept of online trading of agricultural products [19].

2.4. Theories on Product Pricing in the E-Commerce Environment. In daily life, customers can find many attractive products with different price tags. According to the prices on the tags, customers can freely choose and purchase [20]. But, for manufacturers and retailers, a series of factors need to be considered in the pricing of goods and the gains and losses are calculated. It is important to consider not only factors such as internal production costs and sales but also external market competition [21], such as consumer purchases and national policies, and, for fruit, a seasonal agricultural product, it has the characteristics of short sales period and low surplus value. How companies can use the convenient conditions of information transmission in the Internet age to reduce the risks of seasonal products in the sales process and increase profits is a question worthy of study.

2.4.1. Pricing of Homogeneous Products. Many scholars have conducted research on the pricing of homogenized commodities. (1) One of the scholars used the game theory method to discuss a simple supply chain with only one manufacturer and one seller. Two noncooperative models and one cooperative model are studied, based on the commodity pricing under these two models, as shown in Figure 5. (2) Another scholar's discussion method is different. In the case of unclear market demand, in a simple supply chain, through decision-making models and decentralized decision-making pricing models and then using mathematics to solve the problem, the best pricing model is optimized. (3) Another is to study the influence of different market power structures on the optimal pricing strategy in a closed-loop supply chain dominated by manufacturers and retailers. (4) The game theory model is used to study the optimal pricing and advertising strategies in both cooperative and noncooperative situations. (5) The advertising strategy and pricing strategy of two different modes of linear demand and elastic demand under duopoly conditions are studied [22].

2.4.2. Pricing of Heterogeneous Products. With the advancement of technology, transportation has become more flexible and convenient, and people's needs have become more diverse and personalized. The unified pricing process can no longer meet the demand for new products. Product pricing under the condition of diversified product demand has become the focus of hot research [23]. Scholars with different specific research directions gave different solutions. (1) Some scholars have studied the effect of product pricing models on the level of recovery and profit in the case of different acceptance levels of consumer groups. (2) Some scholars have studied the impact of the recycling price of waste products on the differential pricing strategy under the decentralized decision-making and centralized decisionmaking modes in the closed-loop supply chain, taking the recycling process of waste products as the research object. (3) Others have studied the influence of remanufacturing and renovation strategies on product pricing differences considering the different preference attributes of customers for products and studied the dynamic pricing of products in traditional sales channels from different aspects [24].

The above scholars' research has certain reference significance for product pricing in traditional industries or traditional closed-loop supply chains and product pricing in the e-commerce environment. E-commerce has broadened sales channels for enterprises, and, at the same time, it has also increased investment and risk. Online retailers and manufacturers must always pay attention to market trends, care about consumer demands, and ensure after-sales risks, formulate a reasonable return policy and product price policy, improve the after-sales satisfaction of online consumers and corporate reputation, and achieve the company's production and sales goals. Product pricing must consider the changes in market supply and demand. In the era of rapid development of the Internet, product pricing strategies must also consider dynamics and timeliness, so that companies can be in a strong position in market competition [25]. Among them, the influence of e-commerce on supply chain management mainly includes reducing the intermediate links of the supply chain, achieving the purpose of reducing costs through online sales, and making the organizational boundaries of the enterprise tend to be blurred. The company's sales model has changed from being driven by producers to being driven by consumers.

2.5. The Business Model of Fruit and Other Agricultural Products. Instant messaging services are the most important part of the "Internet +" era. People can easily access all media information services through any terminal; that is, the Internet provides important information services about user behavior. Therefore, many literature examine "user" factors when writing related marketing strategies, including customer communication, user heterogeneity, user behavior policies, and social media. 


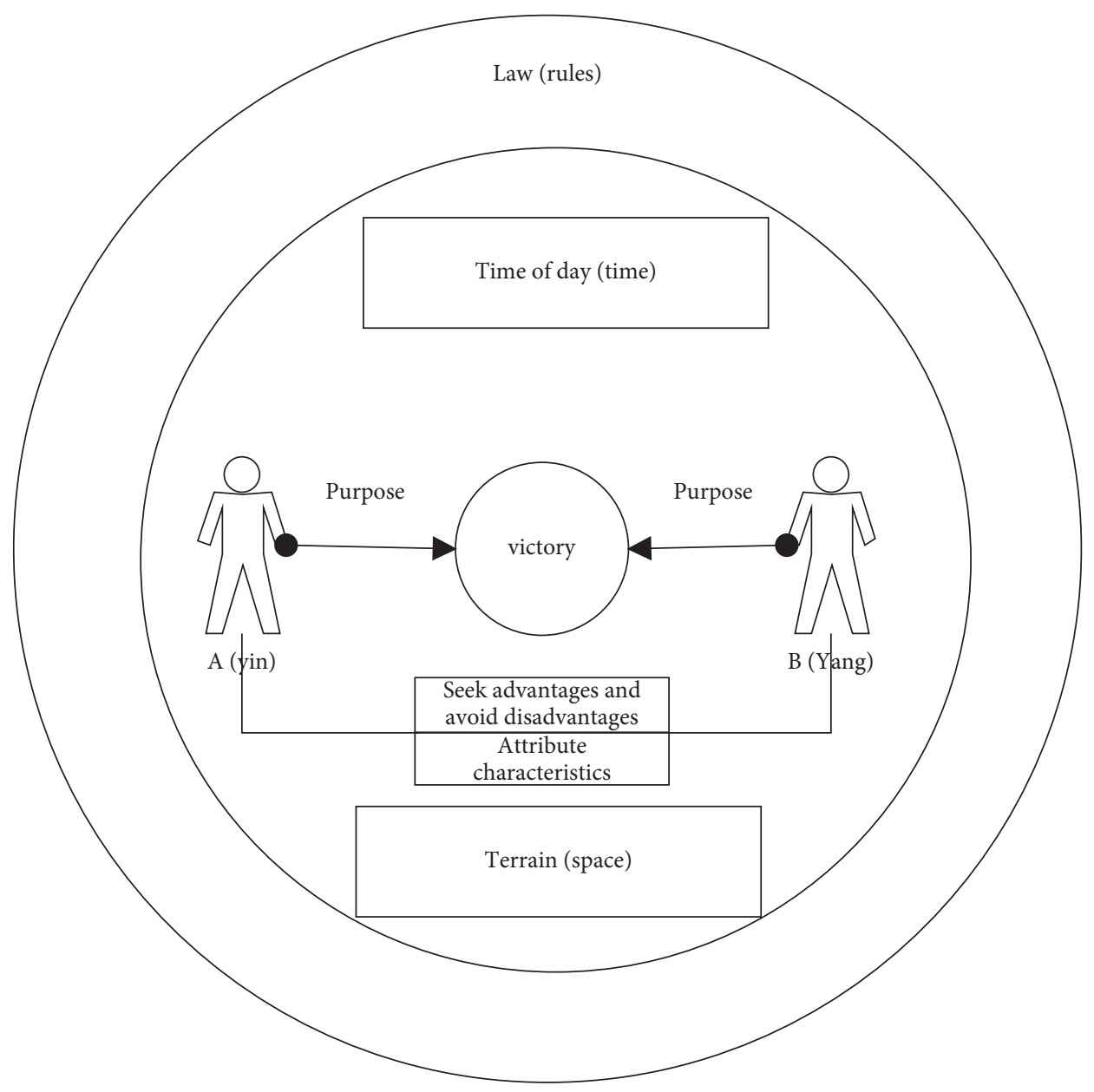

FIgURE 5: Two-party game model.

Based on the different seasons and practices of fruit and other agricultural products, consumers also choose fruits according to supermarkets and fruit shops. Based on the characteristics of fruit, the scale of online sales is not large, and the online sales are supplemented by offline sales of fruits [26]. Regarding the advantages and disadvantages of online and offline sales, it is logistics for online and offline channels, so physical stores have an advantage at this point in time. There are two offline logistics methods, one is selfoperated and the other is third-party logistics, so physical stores have an advantage online in terms of time. The experience is an offline flaw. For products like clothing, the styles are more standardized. If it is a complicated style, you cannot try it on or see the real thing; you can only show and comment on the seller. Purchases are made in the pictures posted by the seller, and you can try on or see the real thing online in the physical store, which also has an advantage in the after-sales. According to the different subjects, it can be divided into three forms:

2.5.1. Wholesalers Centralized Purchasing and Selling. Distributors use funds, experience and product information for analysis, purchase fruits and other agricultural products from farmers, select products with differentiated quality, and then distribute them to many online and offline retailers for different fees. In order for retailers to sell their products as quickly as possible, they must do a lot of marketing work. As the most important link in selling fruits and other agricultural products to consumers, marketing projects are weak for farmers. Suppliers wisely plan storage and transfer to the store based on user request information returned from the market. Retailers are very risky to the market, enabling farmers to control the risks of consumer products within a controllable range, and they can quietly manufacture and plant [27].

However, this business model also has some drawbacks: supporting equipment needs to be improved and products cannot be expanded; communication skills are insufficient, and the communication methods between parties and the ability to organize, analyze, and process information are insufficient. Low income and high sales volume have led to asymmetry in market information, and government management confusion has led to the inability to integrate costs and effectively protect the interests of farmers.

2.5.2. Sales Company + Cooperative Model. Now the "marketing + cooperation" model of agricultural products has reached the point of win-win cooperation and double failure 
in the division of labor, basically solving the problem of market connection between "small farmers" and "big markets." Agricultural cooperatives, with the help of large sales companies and platforms, create or hire professionals to package their products and promote them in a large market, thereby increasing sales and professionalism. Due to the uniqueness of the brand, it naturally improves the competitiveness and productivity of its products. In addition, professional marketing talents connect distributors and customers with higher efficiency than competitors and adjust their products and companies to maximize their overall risk-taking ability. The "sales + collaboration" model is very suitable for the sales needs of important agricultural products, but there are also some problems that need to be resolved quickly. It is only friendly to large-scale cooperation with stable product quality, which will widen the gap between the rich and the poor in the community, and cannot properly solve the problems of farmers' self-reliance, insufficient incentives, insufficient safety guarantees, and inadequate marketing [28].

2.5.3. Self-Employed Sales. Personal sales are also divided into large sales and farmers' direct sales. Large sales operators have strong autonomy, which makes this model still the main sales channel for farmers. The big sellers not only engage in agricultural production themselves but also purchase agricultural products from farmers, and then transport them to other regions for sale, or contact other buyers to buy them at their own premises. Since the big sellers are very familiar with the local environment and sales situation, the acquisition is more boring. On the other hand, because the big sellers can obtain sufficient benefits, they are more motivated to acquire. The disadvantages of this business model include lack of channels, high risks, and limited sales capabilities [29].

\subsection{Fruits and Other Agricultural Products Logistics System}

2.6.1. Overview of E-Commerce Logistics Distribution System for Agricultural Products Such as Fruits

(1) The distribution is diverse and extensive. As a large agricultural country, China is rich in agricultural products. Every year, fruits and other agricultural products have a large output, and these agricultural products are distributed in different regions.

(2) The logistics and distribution service level and logistics distribution of agricultural products such as fruits in large demand have strict requirements on timeliness and freshness. With the frequent emergence of social food security problems, the circulation links of agricultural products such as fruits must play a monitoring and traceability function. On this basis, the products must be delivered to customers on time and in quality and quantity.

(3) Fruits and other agricultural products have very high requirements for transportation equipment, and the distribution of products is different from conventional logistics distribution. Due to the uniqueness of agricultural products, the delivery technology and time requirements of agricultural product distribution are also different.

(4) The logistics and distribution of fruits and other agricultural products are affected by time and season. Due to the seasonal characteristics of fruits and vegetables, the logistics and distribution of agricultural products have also changed over time. In addition, agricultural products are affected by climate and other factors, and the quality and output of agricultural products also vary greatly.

(5) The logistics and distribution of agricultural products such as fruits are one-way logistics and the cost is relatively high. Fruits and other agricultural products are produced in rural areas and eaten in cities, becoming a single road transportation from rural to urban.

Among them, the problems in the development of e-commerce logistics are as follows: the foundation of e-commerce logistics is relatively weak, the development is not perfect, and the logistics industry is relatively backward. Relevant enterprises and users are not paying enough attention to understanding of e-commerce logistics. In terms of logistics information, integrated management, and technical levels, China's industrial and commercial enterprises are generally low. The management and technical level of logistics distribution enterprises need to be improved, and the service network urgently needs to be established and integrated. The shortage of talents is a major obstacle hindering the development of e-commerce logistics, logistics, and distribution management.

2.6.2. E-Commerce Logistics Delivery Mode of Fruit Products. The e-commerce logistics model of fruit and other agricultural products refers to the logistics method that $\mathrm{W}$ company is market-oriented; $\mathrm{W}$ meets the requirements of customers and obtains the general benefits of the optimized system. At present, the main positioning of the project includes self-service distribution services, H-party logistics services, fourth-stage logistics services, and logistics integration services. Among them, the e-commerce logistics distribution models mainly include the domestic postal system distribution mode, the joint distribution mode, and the third-party logistics enterprise distribution mode. According to the organization method, there are mainly three types: self-operated distribution, third-party distribution, and joint distribution. Self-operated distribution mode is a distribution mode widely adopted by current production, circulation, or comprehensive enterprises. Third-party distribution refers to a logistics operation method in which a third-party other than the supplier and demander of the logistics service completes the logistics service. Codistribution is also called shared third-party logistics service, which means that multiple customers are united and jointly provided by a third-party logistics service company to provide distribution services. 
As shown in Figure 6, the distribution model based on the above has many advantages, and information such as agricultural product prices can be easily obtained through the platform, and the information is more transparent. Suppliers trade through relatively fair competition, the prices of agricultural products are relatively reasonable, and they can provide a variety of domestic and foreign agricultural products market quotations and transaction quotations. Both parties need to be able to select various types of agricultural product information push services according to their needs. Among them, the significance of developing rural e-commerce: it is conducive to the optimal allocation of agricultural product market resources, and it changes the operation and management mode of rural industrial production. It is conducive to cultivating and improving the international market position and competitiveness of rural specialty food operators and is conducive to improving the quality of life of the people in rural areas. The logistics of agricultural products have only developed rapidly in recent years and are still in their infancy. There are still some problems. Agricultural products logistics are small in scale and of low level; logistics resource allocation is unreasonable, and basic supporting facilities and equipment are backward; agricultural product logistics information is backward; logistics links are many and the cost is high.

2.7. The Optimal Decision of the Supply Chain. The two-tier supply model of retailers and enterprises is considered; under the influence of cost and product quality, the best decision-making problem between retailers and distributors is studied. When the retailer sends an order to the supplier, the distributor supplies fruits and other agricultural products within the time period of $[t, 1]$. When the quality of the product appears, we should return and exchange the product in time to maintain the reputation of the store.

2.7.1. Retailer's Optimal Sales Decision Calculation Method. In order to stabilize the plan and obtain sufficient time to prepare, suppliers can influence the retailer's sales behavior by controlling prices and sales time:

$\mathrm{K}$ : the total number of potential consumers

$p_{1}$ : retail price at the presale stage

$p_{2}$ : retail price during regular sales season

$\alpha$ : the sensitivity of demand to price $(\alpha>2)$

q: quality, which is the uniform distribution of random variables from $[0,1]$, and the function is $f$ and $q$ is an exogenous variable

$\mathrm{t}$ : the time point when the retailer stops presale $(0<t<1)$

$d_{t}$ : demand in the presale stage

$D_{t}$ : demand in the regular sales season

$S_{t}$ : the order quantity of the retailer during the regular sales season when the presale is stopped at time $t, w_{t}=w_{0}+\delta_{t}$

$w_{0}$ : the fixed wholesale price is an exogenous variable $\delta$ : describes the increase in wholesale price over time $w_{t}$ : the wholesale price set by the manufacturer when the presale is stopped at time $t$

$$
\mathrm{D}(p, q)=K p^{-a} q .
$$

Among them, $a>2$ is the guaranteed profit function, and the operation and maintenance $a$ is obtained through market research. Assuming that the market's demand for products is evenly distributed in various time periods, the conventional sales function is

$$
\begin{aligned}
d_{t} & =t K p_{1}^{-a} E(q), \\
\mathrm{D}_{t} & =(1-t) K_{2}^{-a} p .
\end{aligned}
$$

At the beginning of sales, the unknown market demand is $K p_{1}^{-a} E(q)$. As $t$ increases, the uncertainty of market demand will decrease. When $t$ is 1 , the retailer will use the presold to sell; when $t$ is 0 , the presale method is not adopted to sell agricultural products such as fruits.

In order to obtain the optimal solution for the supply chain between the distributor and the retailer, when the retailer continuously sells between $[0, t]$, the retailer's profit is $p_{1} d_{t}$. The retailer's merchandise volume will inevitably meet the market demand, so the retailer needs to meet the demand for the quarter when the order quantity $Q_{t}$ is higher than the value of $d_{t}$. The expected profit formula is

$$
\prod_{r}=p_{1} d_{t}+\pi\left(p_{2}, S_{t} \mid d_{t}\right)
$$

where

$$
\pi\left(p_{2}, S_{t} \mid d_{t}\right)=p_{2} \min \left(S_{t}, D_{t}\right)-w_{t} S_{t}
$$

According to the maximization of profit, the retailer chooses formula (4) as the best selling price, retail price in the regular season, and order quantity.

For the wholesale price $w_{t}$, the retailer's optimal decision-making formula for presale and regular sales is

$$
\begin{aligned}
& p_{1}=\frac{a}{a-1} w_{t}, \\
& p_{2}=\frac{a+1}{a-1} w_{t}, \\
& S_{t}=2(1-t) K \frac{(a-1)^{a}}{(a+1)^{a+1}} w_{t}^{a} .
\end{aligned}
$$

These 3 formulas prove the profit of the presale stage:

$$
\pi_{1}=p_{1} d_{t}=t K E(q) p_{1}^{-a}\left(p_{1}-w_{t}\right) .
$$

Then the retailer's optimal decision is $\partial \pi_{1} / \partial p_{1}=t K E(q) p_{1}^{-a-1}\left[-(a-1) p_{1}+\alpha w_{t}\right]$, because $a>2$, so $\pi_{l}$ is a function of $p_{l}$; the optimal pricing is

$$
p_{1}=\frac{a}{a-1} w_{t} .
$$

2.7.2. The Calculation Formula of the Optimal Logistics Distribution Path for Fruits and Other Agricultural Products. 


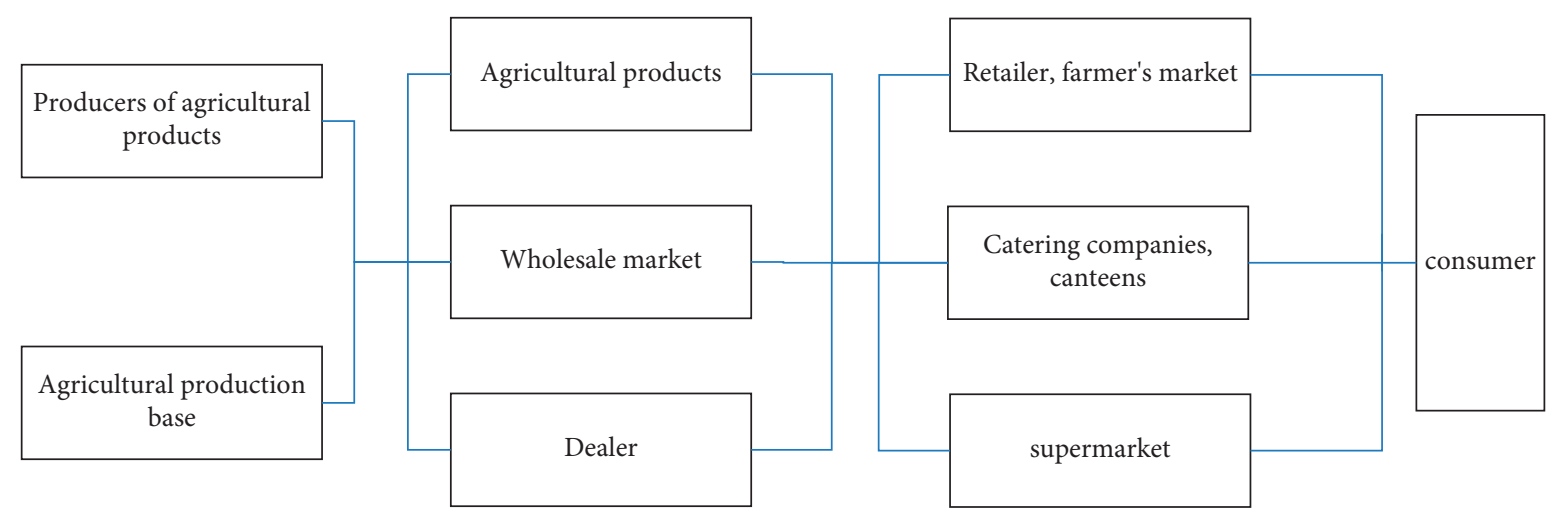

FIGURE 6: The logistics and transportation system diagram of agricultural products such as fruits.

Assume that the mathematical model of vehicle scheduling for distribution products can be described as follows: there are $M$ distribution centers, and the number of vehicles in each distribution center is $K_{m}(m=1, \ldots, M)$, where $K$ is the number of vehicles, delivered to $N$ customers, and the number of goods required by the customer is assumed to be $g_{i}(i=1, \ldots, N)$, and each vehicle will have the maximum load, which is temporarily set as $q_{m k}$. It costs $\mathrm{C}$ yuan to drive the vehicle per hour, $w$ to wait while waiting, and delayed cost $e_{w}$ during driving, and set the distance and speed between the delivery center and the customer; the distance and speed between the customer and the customer are $v_{i j}$ and $d_{i j}$, each customer needs a vehicle to meet the freight volume, and the time is $\left[E T_{i}, L T_{i}\right]$.

As shown in Figure 7, customer satisfaction is calculated according to the time function of goods delivery. The specific satisfaction function is expressed as

$$
f_{t}\left(t_{i}\right)\left\{\begin{array}{l}
0, t_{i}<E T_{i}, \\
0.7 \times \frac{\left(t_{i}-E T_{i}\right)}{\left(E T_{i}^{d}-E T_{i}\right)}+0.3, E T_{i} \leq t_{i} \leq E T_{i}^{d}, \\
1, E T_{i}<t_{i}<L T_{i}^{d}, \\
0.7 \times \frac{\left(L T_{i}-t_{i}\right)}{\left(L T_{i}-L T_{i}^{d}\right)}+0.3, L T_{i}^{d} \leq t_{i} \leq L T_{,_{i}} \\
0, t_{i}>L T_{i},
\end{array}\right.
$$

$$
w_{j}\left(t_{j}\right)=t_{j}-\left(t_{j}+t_{i j}+\mu t_{j}\right) .
$$

and, just after completing task $i$, when driving to task $j$, if the time when vehicle $k$ arrives at $j$ is earlier than the starting service time, then the vehicle must wait at task $j$; then the expression formula is
Set the customer number as $1,2,3, \ldots, N$, and the label of the shipping center is $N+1, N+2 \ldots N+M$; then the variables are

$$
\begin{aligned}
X_{i j m k}\left\{\begin{array}{l}
1, \text { the } k \text { vehicle representing the delivery point } m \text { travels from } i \text { to } j \\
0, \text { other }
\end{array}\right. \\
\min Z=\sum_{m=1}^{M} \sum_{k=1}^{K_{m}} \sum_{i=1}^{M+N} \sum_{j=1}^{M+N} C d_{i j} x_{i j m k}+\sum_{k=1}^{K_{m}} \sum_{m=1}^{M}\left(t_{m k} \times s+e t_{m k} \times e s\right) \\
+w \times \sum_{i=1}^{N} \max \left(E T_{i}-t_{i}, 0\right)+e w \times \sum_{i=1}^{N} \max \left(t_{i}-L T_{i}, 0\right) .
\end{aligned}
$$




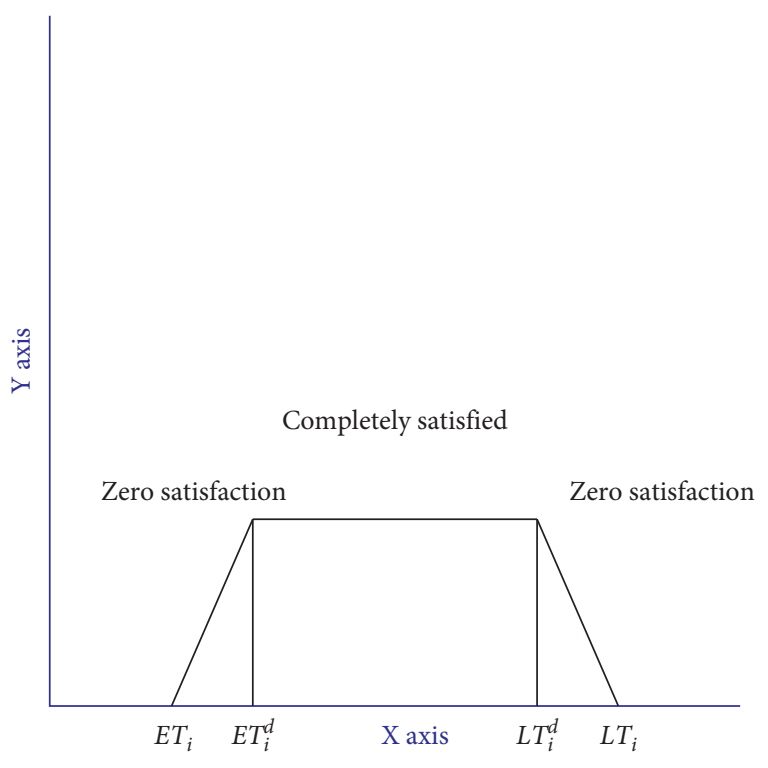

FIgURE 7: Customer satisfaction graph.

This formula is the objective function, and it can be used to calculate the minimum transportation cost $t_{i}$ after the vehicle has been transported to all customers, as shown in Figure 8 .

The constraints of this formula are as follows:

$$
\frac{1}{\mathrm{~N}} \sum_{i=1}^{\mathrm{N}} f_{i}\left(t_{i}\right) \geq 85 \%
$$

The formula expresses the customer satisfaction constraint, and it is necessary to ensure that the average customer satisfaction is greater than $85 \%$.

$$
\begin{gathered}
\sum_{j=1}^{M+N} \sum_{m=1}^{M} \sum_{k=1}^{K_{m}} x_{i j m k}=1, \quad i \in\{1,2, \ldots, N\}, \\
\sum_{j=1}^{M+N} \sum_{m=1}^{M} \sum_{k=1}^{K_{m}} x_{i j m k}=1, \quad \mathrm{j} \in\{1,2, \ldots, N\} .
\end{gathered}
$$

These two formulas indicate that each customer's goods can only be transported by one truck.

$$
\sum_{\mathrm{j}=1}^{\mathrm{N}} \sum_{k=1}^{K_{M}} x_{i j m k} \leq \sum_{m=1}^{M} K_{m}, \quad i=m \in\{N+1, N+2, \ldots, N+M\} \text {. }
$$

This formula indicates that the number of vehicles that also carry out delivery tasks in each delivery should be less than or equal to the total number of vehicles also owned in all deliveries.

$$
\begin{aligned}
& \sum_{i=1}^{N} g_{i} \sum_{j=1}^{M+N} x_{i j m k} \leq q_{m k}, \quad m \in\{N+1, N+2, \ldots, N+M\} \\
& k \in\left\{1,2, K_{m}\right\} .
\end{aligned}
$$

The formula expresses the limitation of the maximum load of the transport vehicle.

$$
\sum_{j=N+1}^{M+N} x_{i j m k}=\sum_{j=N+1}^{M+N} x_{i j m k}=0, \quad i=m \in\{N+1, N+2, \ldots, N+M\}, k \in\left\{1,2, K_{m}\right\} .
$$

This formula means that the vehicle that transports goods needs to transport one or more customers from the delivery center before returning to the delivery center.

\section{Experiments on the Delivery Algorithm of Fruits and Other Agricultural Products}

According to the above analysis, the formula is used to calculate the optimal transportation path of agricultural products such as fruit products. Among the factors considered for the best transportation route are road conditions, weather conditions, and emergencies. The parameters are set to $R=80$, the maximum algebra $G=150$, the selection probability $=0.8$, and the accident probability $=0.02$. For this experiment, the data generated by the delivery process of the distribution center is used as the research object, and the rationality of the data verification algorithm is obtained through calculation. The process of a distribution center delivering goods for 12 customers is used as the specific experimental data, the order is received on the e-commerce platform on the first day, and the shipment will start on the second day. The specific data is shown in Table 1 .

Because the actual distance of the road section is different from the transportation path, there is a certain error in the transportation process. In the process of delivering to the customer, because of the special nature of the fruit, each vehicle needs to be equipped with freshkeeping equipment to ensure that the fruit is fresh when delivered to the customer. The vehicles transported are unified as small electric vehicles with a maximum load of $15 \mathrm{KG}$. The transportation cost of this electric vehicle is 0.5 yuan per kilometer, and the speed of the vehicle is $60 \mathrm{Km} / \mathrm{h}$. Under normal circumstances, the salary is 10 yuan per hour, and overtime is doubled; vehicle waiting is 10 yuan per hour, and the delay fee is 100 yuan per hour; the start time is about $6: 30$ every day, and the winter time is delayed by 1 hour.

After collecting statistics on the fruit sales data of a certain website, the basic information of the fruit purchasers is collected as shown in Table 2. 


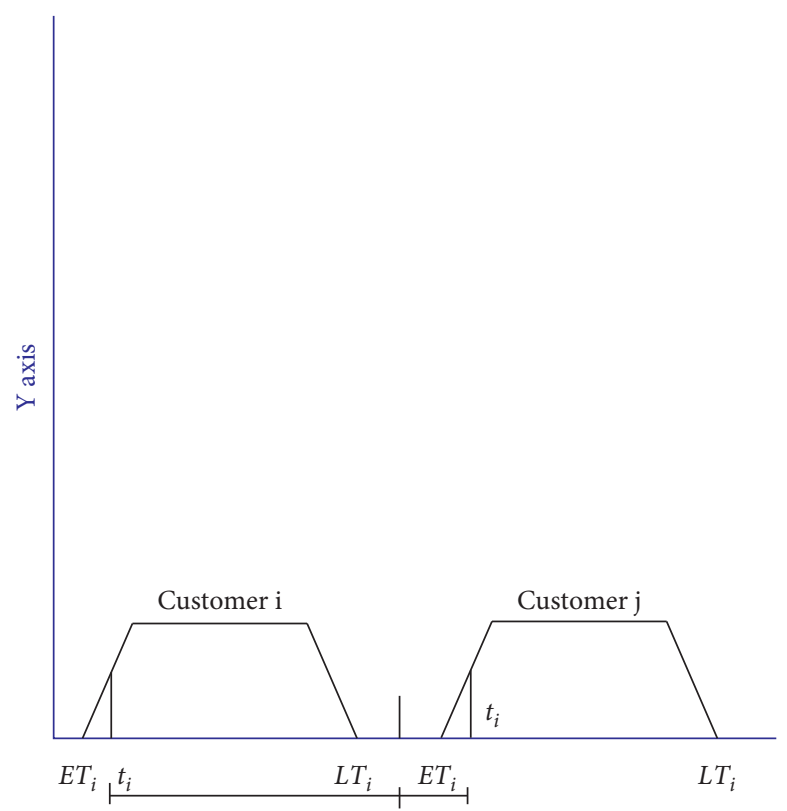

FIgURE 8: Customer waiting time chart.

TABLE 1: Fruit transportation data graph.

\begin{tabular}{|c|c|c|c|c|c|}
\hline Code name & Name & Cargo volume/t & Delivery time/min & Time window & Fuzzy operation time \\
\hline 0 & Customer 1 & 2.5 & 15 & {$[8: 00,17: 00]$} & {$[9: 00,12: 30]$} \\
\hline 1 & Customer 2 & 3 & 25 & {$[8: 00,10: 30]$} & {$[8: 30,10: 30]$} \\
\hline 2 & Customer 3 & 2.5 & 20 & {$[8: 00,17: 00]$} & {$[9: 00,15: 30]$} \\
\hline 3 & Customer 4 & 5.5 & 30 & {$[8: 00,12: 00]$} & {$[8: 30,12: 30]$} \\
\hline 4 & Customer 5 & 3.5 & 25 & {$[8: 00,8: 30]$} & {$[8: 30,9: 30]$} \\
\hline 5 & Customer 6 & 3 & 20 & {$[8: 00,17: 00]$} & {$[10: 30,14: 30]$} \\
\hline 6 & Customer 7 & 5.5 & 30 & {$[8: 00,17: 00]$} & {$[8: 30,12: 30]$} \\
\hline 7 & Customer 8 & 5.5 & 30 & {$[8: 00,11: 00]$} & {$[9: 00,10: 30]$} \\
\hline 8 & Customer 9 & 5 & 35 & {$[8: 00,9: 00]$} & {$[8: 30,9: 00]$} \\
\hline 9 & Customer 10 & 4.5 & 30 & {$[8: 00,14: 00]$} & {$[8: 30,18: 30]$} \\
\hline 10 & Customer 11 & 5 & 30 & {$[8: 00,13: 30]$} & {$[10: 30,12: 30]$} \\
\hline 11 & Customer 12 & 5.5 & 30 & {$[8: 00,16: 00]$} & {$[9: 00,15: 30]$} \\
\hline
\end{tabular}

TABLE 2: Information table of online fruit shoppers.

\begin{tabular}{lccc}
\hline Adjusted content & & Number of people & Percentage \\
\hline \multirow{2}{*}{ Gender } & Male & 182 & 44.28 \\
& Female & 229 & 55.72 \\
\hline \multirow{4}{*}{ Age } & 25 or less & 131 & 31.87 \\
& $25-30$ & 166 & 40.39 \\
& $31-40$ & 94 & 22.87 \\
& $41-50$ & 14 & 3.41 \\
& Above 50 & 6 & 1.46 \\
\hline
\end{tabular}

\section{E-Commerce Data Experiment}

4.1. Experiments on Logistics and Transportation of Agricultural Products Such as Fruits. According to the above formula, the data in Table 1, the vehicle scheduling plan in the case of taking into account the customer's satisfaction, and the cost and time spent in transporting fruits and other agricultural products from the delivery point to the customer's home are substituted into the calculation, as shown in Table 3.
According to the transportation methods in Table 3, the customer recognition is not high. In order to obtain higher customer recognition, choose to improving the vehicle scheduling method is chosen. The specific scheduling method is shown in Table 4.

As shown in Figure 9, regardless of customer satisfaction with running fruit and other agricultural products, the cost of transportation is 586 yuan, and the average delivery time of vehicles is 5.625 hours, but the average satisfaction is only $78.5 \%$, and the value is low. 
TABLE 3: Vehicle scheduling without considering customer satisfaction.

\begin{tabular}{|c|c|c|c|c|c|c|c|}
\hline Vehicle & Loading & Loading rate $(\%)$ & Path & Journey & Time/min & Cost & Satisfaction (\%) \\
\hline Vehicle 1 & 14 & 93.3 & $-8-1-10-3-$ & 383 & 8 & 222 & 75 \\
\hline Vehicle 2 & 13 & 86.7 & $-6-7-12-$ & 241 & 5.5 & 133 & 77 \\
\hline Vehicle 3 & 11 & 73.3 & $-5-11-2-$ & 207 & 4.5 & 115 & 84 \\
\hline Vehicle 4 & 12. & 80.0 & $-9-4-0-$ & 211 & 4.5 & 116 & 78 \\
\hline
\end{tabular}

TABLE 4: Optimized scheduling plan.

\begin{tabular}{lccccccc}
\hline Vehicle & Loading & Loading rate (\%) & Path & Journey & Time/min & Cost & Satisfaction (\%) \\
\hline Vehicle 1 & 13 & 86.7 & $-5-12-7-$ & 253 & 5.5 & 143 & 99.6 \\
Vehicle 2 & 14.5 & 96.7 & $-9-4-6-$ & 232 & 5 & 132 & 99.6 \\
Vehicle 3 & 10 & 66.7 & $-10-2-11-$ & 293 & 6.5 & 164 & 99.5 \\
Vehicle 4 & 12.5 & 83.3 & $-8-1-3-$ & 291 & 6 & 162 & 99.4 \\
\hline
\end{tabular}
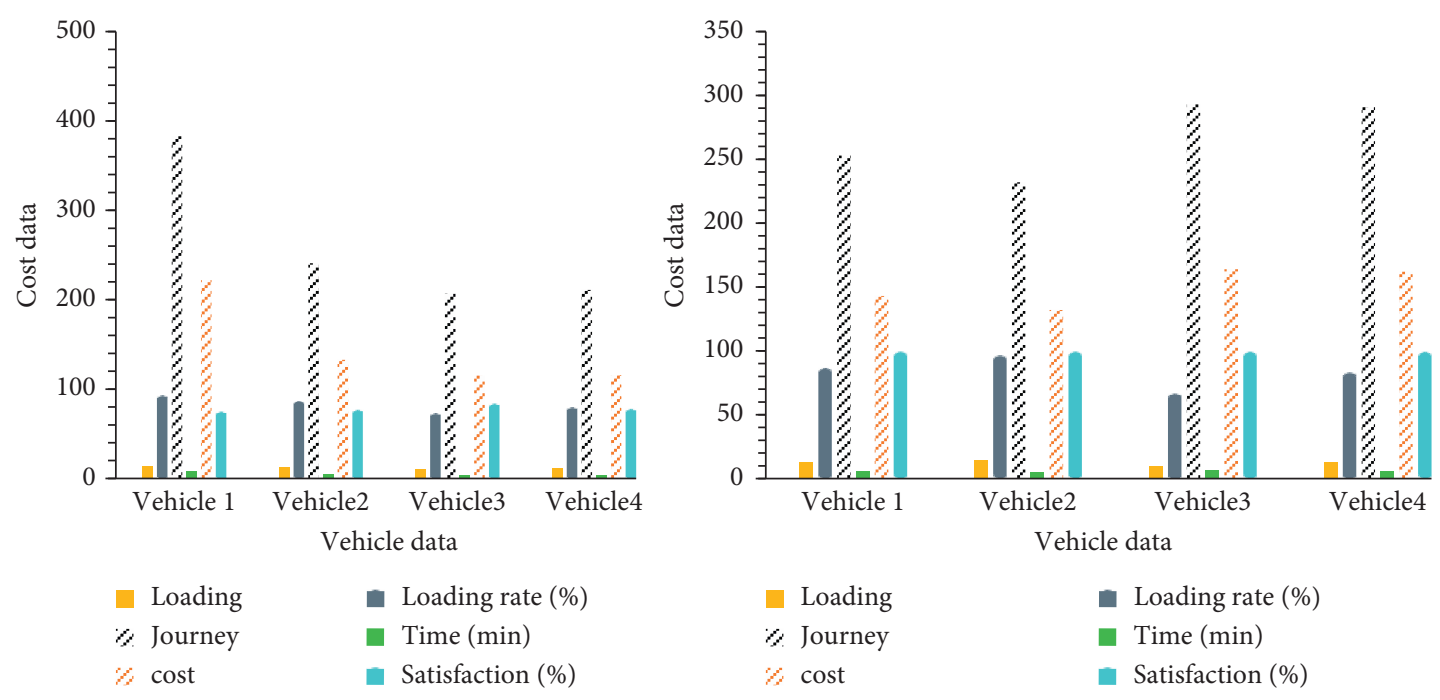

Figure 9: Data diagram of transportation vehicle scheduling plan.
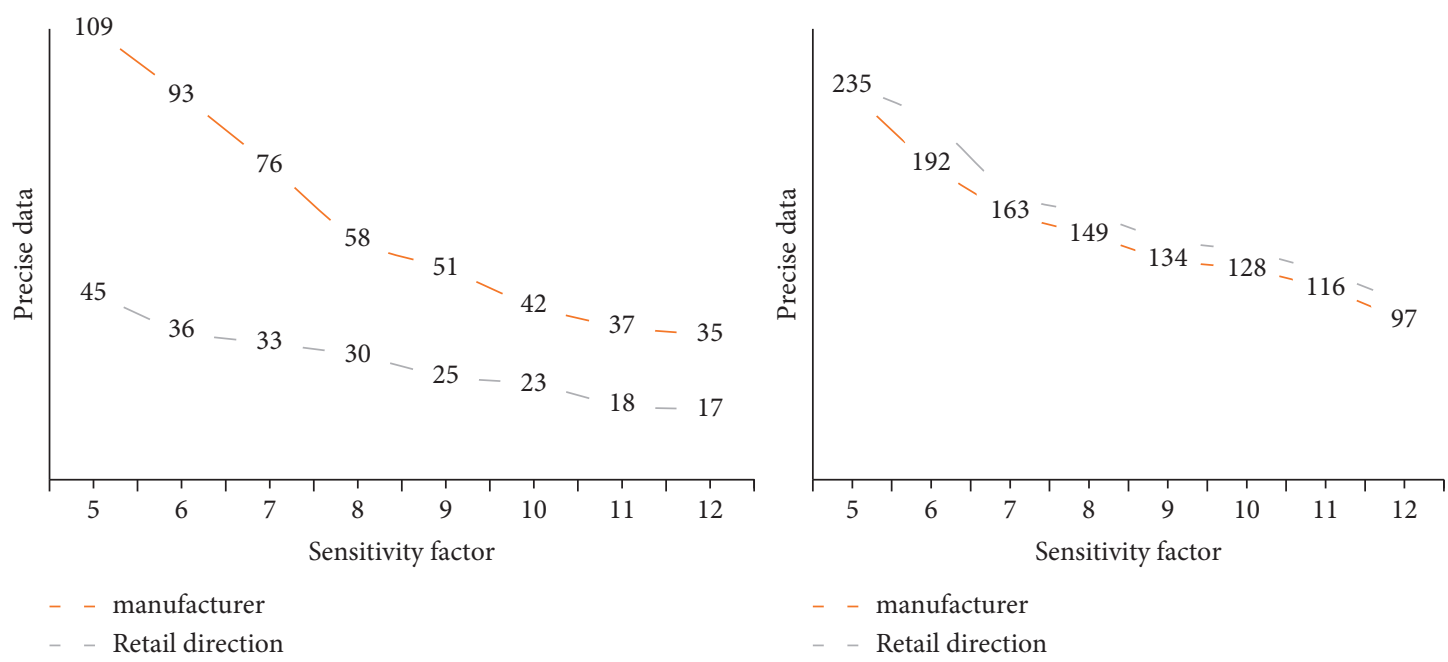

Figure 10: The effect of $\beta$ sensitivity coefficient on pricing and returns.

After considering the customer's satisfaction, the total cost is 601 yuan, the average delivery time of the vehicle is 5.75 hours, and the customer satisfaction rate is $99.525 \%$.
Comparing the data on the two sides, the cost and time have not increased excessively after considering the customer. The use of the vehicle is also in an ideal state, 
and there will be no damage due to excessive use of the vehicle. The delivery time is also very timely, ensuring the freshness of the fruit.

4.2. Product Price Sensitivity Coefficient. This coefficient is used to discuss the impact of consumers' sensitivity to retailer's product pricing in the range of 5 to 12 , the impact on various decisions, and the impact of dealers and retailers on the optimal profit.

As shown in Figure 10, as the product pricing sensitivity coefficient $\beta$ increases, whether they are retail dealers or dealers, they are in a downward trend under a market-based structure. The higher the sensitivity coefficient of the product on the market, the lower the price data on the market.

\section{Conclusion}

According to the current development form of e-commerce, traditional logistics methods have been difficult to meet current needs. Especially in recent years, the rapid development of fruit and other agricultural products in e-commerce is aimed at the peculiarities of fruit and other agricultural products, resulting in higher requirements for logistics transportation. This article summarizes and improves all aspects of fruit and other agricultural products from ordering to transportation and builds an e-commerce system based on fruits and other agricultural products, which can quickly deliver fruits and other agricultural products to customers on the basis of cost savings. The optimal sales decision plan of the retailer is analyzed, so that the retailer can obtain greater benefits in the process of sales. As the primary industry, fruit and other agricultural products are inherently disadvantaged in today's fiercely competitive market, but fruit and other agricultural products are also in great demand. There are some problems in the traditional fruit and other agricultural products market. The combination of e-commerce and fruit and other agricultural products industry can empower the traditional industry of fruit and other agricultural products. There is huge room for the development of e-commerce of agricultural products such as fruits, and enterprises attach importance to customers' repurchase intentions and the sustainable and healthy development of e-commerce of fresh agricultural products. In the future, the scale and quality of e-commerce for agricultural products such as fruits will surely be developed by leaps and bounds [30].

\section{Data Availability}

No data were used to support this study.

\section{Conflicts of Interest}

The authors declare that there are no conflicts of interest.

\section{References}

[1] D. Chen, P. Wawrzynski, and Z. Lv, Cyber Security in Smart Cities: A Review of Deep Learning-Based Applications and Case Studies, Sustainable Cities and Society, Article ID 102655, 2020.

[2] C. He and J. Gao, "Research on warehouse and distribution integration of fresh products cold chain logistics under the background of E-business," Boletin Tecnico/Technical Bulletin, vol. 55, no. 8, pp. 10-20, 2017.

[3] M. Ito, "Online sales of fruit and vegetables: current state and trends," Journal for the Integrated Study of Dietary Habits, vol. 29, no. 1, pp. 17-21, 2018.

[4] H. Shaosheng Jin, "Preferences of Chinese consumers for the attributes of fresh produce portfolios in an e-commerce environment," British Food Journal, vol. 119, no. 4, pp. 817-829, 2017.

[5] K. Nir, "5G in E-commerce activities," IT Professional, vol. 20, no. 4, pp. 73-77, 2018.

[6] M. W. Hasanat, A. Hoque, and A. B. A. Hamid, "E-commerce optimization with the implementation of social media and seo techniques to boost sales in retail business," Journal of Marketing and Information Systems, vol. 03, no. 1, pp. 1-5, 2020.

[7] X. Ma, W. Li, and J. Wu, "Research on the operation of e-commerce enterprises based on blockchain technology and bilateral platforms," Wireless Communications and Mobile Computing, vol. 2021, no. 1, pp. 1-10, 2021.

[8] K. H. Leung, K. L. Choy, P. K. Y. Siu, G. T. S. Ho, H. Y. Lam, and C. K. M. Lee, "A B2C e-commerce intelligent system for re-engineering the e-order fulfilment process," Expert Systems with Applications, vol. 91, no. jan, pp. 386-401, 2018.

[9] Z. Lv and H. Song, "Mobile Internet of things under data physical fusion technology," IEEE Internet of Things Journal, vol. 7, 2019.

[10] J. Mou, Y. Cui, and K. Kurcz, "Bibliometric and visualized analysis of research on major e-commerce journals using citespace," Journal of Electronic Commerce Research, vol. 20, no. 4, pp. 219-237, 2019.

[11] L. Vanneschi, D. M. Horn, M. Castelli, and A. Popovič, "An artificial intelligence system for predicting customer default in e-commerce," Expert Systems with Applications, vol. 104, no. aug, pp. 1-21, 2018.

[12] L. Yu, "Correction to: a novel E-commerce model and system based on $\mathrm{O} 2 \mathrm{O}$ sports community," Information Systems and E-Business Management, vol. 18, no. 4, p. 1, 2020.

[13] J. Liu, C. Liu, L. Zhang, and Y. Xu, "Research on sales information prediction system of e-commerce enterprises based on time series model," Information Systems and E-Business Management, vol. 18, no. 4, pp. 823-836, 2020.

[14] Z. Lv and L. Qiao, "Deep belief network and linear perceptron based cognitive computing for collaborative robots," Applied Soft Computing, vol. 92, p. 106300, 2020.

[15] Z. Guo, D. Zhang, J. Li, S. Lin, S. Feng, and Y. Xiao, "The design of a remote fitting system for garment e-commerce," Journal of the Textile Institute, vol. 110, no. 2, pp. 243-253, 2019.

[16] K. H. Leung, K. L. Choy, G. T. S. Ho, C. K. M. Lee, H. Y. Lam, and C. C. Luk, "Prediction of B2C e-commerce order arrival using hybrid autoregressive-adaptive neuro-fuzzy inference system (AR-ANFIS) for managing fluctuation of throughput in e-fulfilment centres," Expert Systems with Applications, vol. 134, no. NOV, pp. 304-324, 2019. 
[17] A. Huang, "A risk detection system of e-commerce: researches based on soft information extracted by affective computing web texts," Electronic Commerce Research, vol. 18, no. 1, pp. 143-157, 2018.

[18] M. Li, L. Shen, and G. Q. Huang, "Blockchain-enabled workflow operating system for logistics resources sharing in E-commerce logistics real estate service," Computers \& Industrial Engineering, vol. 135, no. SEP, pp. 950-969, 2019.

[19] J. Si, X. Zhang, M. Li et al., "Wearable wireless real-time cerebral oximeter for measuring regional cerebral oxygen saturation," Science China Information Sciences, vol. 64, no. 1, pp. 1-10, 2021.

[20] D. Yuan, V. F. Fusco, and A. Shitvov, "Beam index modulation wireless communication with analog beamforming," IEEE Transactions on Vehicular Technology, vol. 67, no. 7, pp. 6340-6354, 2018.

[21] S.-zan Zhan, "Study on the focus strategy of e-commerce enterprise under the background of 'Internet+," A case study of Kunming Ch999, vol. 2021, no. -2, pp. 191-200, 2016.

[22] M. Filipe and Lins, "Register file criticality and compiler optimization effects on embedded microprocessor reliability," IEEE Transactions on Nuclear Science, vol. 64, no. 8, pp. 2179-2187, 2017.

[23] R. Sato, Y. Hatanaka, Y. Ando et al., "High-speed operation of random-access-memory-embedded microprocessor with minimal instruction set architecture based on rapid singleflux-quantum logic," IEEE Transactions on Applied Superconductivity, vol. 27, no. 4, pp. 1-5, 2017.

[24] I. Hida, S. Takamaeda-Yamazaki, and M. Ikebe, "A high performance and energy efficient microprocessor with a novel restricted dynamically reconfigurable accelerator," Circuits and Systems, vol. 08, no. 5, pp. 134-147, 2017.

[25] W. Peng, Y. Zhang, and J. Dan, "ARM-based embedded detection system of cardiovascular function parameters," Zhongguo yi liao qi xie za zhi = Chinese journal of medical instrumentation, vol. 41, no. 2, pp. 79-83, 2017.

[26] K. Konopko and D. Janczak, "Nonlinear signal processing with minimization of spectral distortion for embedded systems," IFAC-PapersOnLine, vol. 51, no. 6, pp. 450-455, 2018.

[27] R.-B. Patmos, "A time-predictable microprocessor," Computing Reviews, vol. 59, no. 12, p. 660, 2018.

[28] T. R. Halfhill, "Achronix debuts FPGAs for AI," Microprocessor Report, vol. 33, no. 6, pp. 23-27, 2019.

[29] B. Wheeler, "SiFive raises RISC-V performance," Microprocessor Report, vol. 32, no. 11, pp. 11-67, 2018.

[30] W. Bob, "Flex logix diversifies eFPGA," Microprocessor Report, vol. 32, no. 7, pp. 30-32, 2018. 